These accounts"no doubt refer to the same meteor as that observed at Hardwick.

Tyndale House, Ashley Down, Bristol, Jan. 8

\section{Blowpipe Analysis}

MAjor Ross (NATURE, vol. xiii. p. 186) does not appear to have thought of the impurities his soda might contain in his test for the presence of a sulphide. Had he done so he would probably have remembered that all soda (unless specially prepared from sodium) contains traces of iron. This iron, on fusing with the sulphide, forms ferrous sulphide, which, as is well known, is soluble in fused sodium sulphide; and on adding water to the fused mass a black residue of ferrous sulphide remains behind.

Again, he says "there can be no room to precipitate anything in a drop of water;" but surely this is erroneous. It is only a question of degree. Under the same circumstances a precipitate would be as certainly formed in a drop of water as in a gallon.

If Major Ross were to make allowances for the ordinary impurities of commercial reagents, a little more confidence might be placed in his tests.

T. S. HUMPIDGE

\section{Marine Aquaria}

WHILE reading Mr. Wills's very suggestive article on Marine Aquaria in your last issue, the following question suggested itself to me :-Does not the "larger proportion of carbonic acid in the lowest depths of the ocean "explain, at any rate partially, the formation of the "abyssal red clay," which Prof. Wyville Thomson has proved to occupy so large a portion of the bed of the Atlantic?

"Many of the insoluble carbonates, and in particular those of lime, magnesia, \&c., may be dissolved to some extent by water, charged with carbonic acid, and are deposited in a crystalline form, as the gas slowly escapez from the fluid." (Miller's "Chemistry.")

That the presence of carbonic acid in the deep water is one cause of the decomposition of the shells of Mollusca, \&c., I think that there can hardly be a doubt. Whether it is sufticient by itself to account for the whole phentomenon, I cannot presume to decide.

Bournemouth, Jan. 10

\section{The Glow-worm in Scotland}

Mr. J. SHAw's interesting note on the Glow-wirm leads me to remark that it is common about Loch Lomond, and recalls the pleasant surprise with which I met one there, shining briliantly by the wayside, so late as twelve o'clock on a dark midsummer's night.

London, Jan. to

WM. MCLAURIN

\section{Bryant and May's Safety Matches}

TuEse matches are highly electrical, and if they be rubbed again st glass and ebonite they ignite, especially if the electrics be dry and warm. How far their ready ignition on amorphous phosphorus is dite to chemism or to electricity remains to be proved. I am sorry I have not the opportunity just now to test this point.

W. H. PREECE

\section{OUR ASTRONOMICAL COLUMN}

The Minor Planet, No. I53.-This planet, discovered by Palisa at Pola on Nov. 2, 1875 , and which has been named Hilda by Prof. Oppölzer, is found to have a period of revolution considerably longer than any other member of the group. In No. 39 of Prof. Tietjen's "Berlin Circular" is an orbit calculated by Dr. Schmidt, which represents closely the observations to the end of the year. It is as follows:-

Epoch 1875, Nov, 22, at Berlin midnight.

$\left.\begin{array}{llrlrl}\text { Mean anomaly } & \ldots & \ldots & 108^{\circ} & 3^{\prime} & \mathrm{ri}^{\prime \prime} \\ \text { Longitude of perihelion } & \ldots & 284 & 4 \mathrm{r} & 5^{\circ} \\ \begin{array}{l}\text { Longitude of ascending node } \\ \text { Inclination to ecliptic }\end{array} & \ldots & 228 & 20 & 43\end{array}\right\} \mathrm{r} 875^{\circ} \mathrm{O}$

The major semi-axis is $3^{\circ} 9474$, and if we calculate th distance of the comet from the orbit of Jupiter at the aphelion passage, we find it 0.864 , the earth's mean dis. tance from the sun being taken for unity, which is a much closer approach to Jupiter's path than occurs with any other of the minors. Themis, for instance, the motion of which was investigated by Dr. Krueger, for determination of the mass of Jupiter, does not approach that planet within about $\mathrm{I}^{\prime} 5$. More than one of the small planets with the longer periods have large heliocentric latitude at the aphelion point, and do not on that account approach so near to the orbit of Jupiter as others with shorter periods and somewhat greater excentricities, and having the lines of nodes and apsides less divergent. Cybele in aphelion is $I^{\prime} 3 \mathrm{I}$ from the orbit of the great planet, Freia I'24, and Camilla, according to the rather uncertain orbits yet available, $\mathrm{I}_{3} 3$. Hence, as suggested by Palisa, his planet Hilda is well situated for further investigation on the mass of Jupiter by the perturbations of the minor planets ; it is well known, however, that this important element in the solar system is now reduced within narrow limits of uncertainty.

The above orbit of Hilda is confirmed by another computed by Herr Kühnert of Vienna from a similar extent of observations. The period of revolution is about 2,865 days, or approaching eight years, contrasting strikingly with the period of Flora, which is only $\mathbf{I}, \mathbf{1} 93$ days, or a little over $3 \frac{1}{4}$ years.

SATELLITES OF URANUS.-The following positions of the brighter satellites of Uranus are derived as before from Newcomb's Tables in the Appendix to the Washington Observations for 1873 ; they are for $\mathrm{Irh}$. 30m. P.M. Greenwich time :-

\begin{tabular}{|c|c|c|c|c|c|c|c|c|c|}
\hline & & & & $I A$ & & & & & \\
\hline & & & Angle. & & Dist. & & Angle. & & Dist. \\
\hline Jan. & 15 & $\cdots$ & $23^{\circ} 2$ & $\ldots$ & $3^{\prime \prime} \cdot \mathrm{r}$ & $\ldots$ & $66^{\circ} \cdot 5$ & $\ldots$ & 238 \\
\hline$"$ & 16 & $\ldots$ & 34 & $\ldots$ & 346 & $\ldots$ & $34^{\circ} 9$ & $\ldots$ & $35^{\circ}$ \\
\hline " & $\times 7$ & $\cdots$ & 3477 & $\ldots$ & 431 & $\ldots$ & $18 \cdot 5$ & $\ldots$ & $44^{\circ} 0$ \\
\hline " & I8 & $\ldots$ & $268 \cdot 7$ & $\ldots$ & $15 \cdot 8$ & $\cdots$ & $6 \cdot I$ & $\cdots$ & $46 \cdot I$ \\
\hline , & 19 & $\ldots$ & 212.5 & $\ldots$ & 272 & $\ldots$ & 3526 & $\ldots$ & 40.5 \\
\hline$"$ & 20 & $\ldots$ & $100^{\circ} 1$ & $\ldots$ & $34 \cdot 6$ & $\ldots$ & $33 x^{\prime} 2$ & $\ldots$ & 295 \\
\hline$"$ & $2 \mathrm{I}$ & $\cdots$ & $169^{\circ} I$ & $\ldots$ & 28.9 & $\ldots$ & 286.7 & $\ldots$ & $21 \cdot 1$ \\
\hline & 22 & $\ldots$ & $120 . \mathrm{r}$ & $\ldots$ & 16.5 & $\ldots$ & 2354 & $\ldots$ & $26 \cdot 5$ \\
\hline$"$ & 23 & $\ldots$ & 454 & $\ldots$ & $22 \cdot 4$ & $\ldots$ & 2097 & $\ldots$ & 37.9 \\
\hline 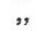 & 24 & $\ldots$ & 16.9 & $\ldots$ & 334 & $\ldots$ & $195^{\circ} 0$ & $\ldots$ & 453 \\
\hline$"$ & 25 & $\ldots$ & 3575 & $\ldots$ & 321 & $\ldots$ & $1 \$ 27$ & $\ldots$ & 453 \\
\hline 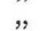 & 26 & $\cdots$ & $324^{\prime}=$ & $\cdots$ & $20 \% 2$ & . & 1680 & $\ldots$ & 37.5 \\
\hline 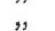 & 27 & . & $245^{\circ} 2$ & $\ldots$ & 18.0 & $\ldots$ & $142 \%$ & $\ldots$ & $26 \cdot 5$ \\
\hline 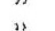 & $2 \dot{S}$ & $\ldots$ & $202 \cdot 6$ & $\ldots$ & $30 \cdot 5$ & $\ldots$ & 90.8 & $\ldots$ & $2 I \cdot I$ \\
\hline
\end{tabular}

THE GREAT COMETS OF 1874 Aind $1680 .-$ Now that the orbit of the fine come of 1874 (Coggia, April I7), determined from the observations in the northern hemisphere to the middle of July, has been shown by the southern observations extending to October, to require but small corrections, we may examine with confidence the path of the comet about the passage of the descending node, when it approached near to the orbit of Venus.

Employing the elements calculated by Dr. Geelmuyden, of the Observatory, Christiania, we have the following results :-

\begin{tabular}{|c|c|c|c|c|c|c|c|c|c|}
\hline \multicolumn{3}{|c|}{$\begin{array}{c}\text { Heliocentric } \\
\text { Ecliptic Longitude. }\end{array}$} & \multicolumn{5}{|c|}{$\begin{array}{l}\text { Heliocentric } \\
\text { South Latituce. }\end{array}$} & \multicolumn{2}{|c|}{$\begin{array}{l}\text { Distance of Comet } \\
\text { from Orbit of Venus. }\end{array}$} \\
\hline $299^{\circ}$ & $45^{\prime}$ & $\ldots$ & $\ldots$ & $2^{\circ}$ & $17^{\prime}$ & $48^{\prime \prime}$ & $\ldots$ & $\ldots$ & 0.003655 \\
\hline 299 & 48 & $\ldots$ & $\ldots$ & 2 & 24 & 38 & $\ldots$ & $\ldots$ & 0.003181 \\
\hline 299 & $5 \mathrm{I}$ & $\ldots$ & $\ldots$ & 2 & $3 r$ & 29 & $\ldots$ & $\ldots$ & 0.003323 \\
\hline 300 & 0 & $\ldots$ & $\ldots$ & 2 & $5 I$ & 58 & $\ldots$ & $\ldots$ & 0.006372 \\
\hline
\end{tabular}

Therefore, assuming the solar parallax $8^{\prime \prime} \cdot 875$, with Clarke's semi-diameter of the earth's equator, the least distance of the comet from the orbit of Venus is found to have been 293,000 miles, or only about one-fourth greater than the distance of the moon from the earth.

A very celebrated comet, that of 1680 , approached the earth's orbit within even less than this distance. From the definitive elements of Encke it would appear that in $92^{\circ} 3^{\prime} 5$ heliocentric longitude, just before traversing the plane of the ecliptic, towards the south, the comet's dis- 